\title{
Criopreservação de sementes de rainha do abismo (Sinningia leucotricha) ${ }^{(1)}$
}

\author{
VANESSA STEGANI(2), GUILHERME AUGUSTO CITO ALVES(3), \\ DOUGLAS JUNIOR BERTONCELLI ${ }^{(3)^{*}}$, RICARDO TADEU DE FARIA(4)
}

\begin{abstract}
RESUMO
A criopreservação pode ser considerada um dos métodos mais baratos e práticos de conservação de material genético por tempo indeterminado. O objetivo do trabalho foi avaliar o uso de soluções criogênicas na criopreservação de sementes de Sinningia leucotricha pelo método de vitrificação em nitrogênio líquido (NL). Os tratamentos avaliados foram: T1 - controle: sem solução crioprotetora; T2 - PVS1; T3 - PVS1 modificado; T4 - PVS2; T5 - PVS2 modificado; T6 - PVS3; T7 - PVS3 modificado; T8 PVS2 $+1 \%$ de floroglucinol. O delineamento foi inteiramente casualizado com oito tratamentos e cinco repetições, compostas por 100 sementes cada. Após 15 dias da imersão das sementes em nitrogênio líquido, os criotubos foram removidos e rapidamente descongelados à temperatura de $40^{\circ} \mathrm{C}$, em banho de água, durante 1,5 minuto. Em seguida, as sementes foram lavadas com solução de lavagem por 20 minutos. Posteriormente foram submetidas ao teste de germinação, sobre papel mata-borrão umedecido com água destilada acondicionado em caixas de poliestireno cristal mantidas em câmara de crescimento (tipo B.O.D.) à temperatura de $25 \pm 2{ }^{\circ} \mathrm{C}$ e fotoperíodo de 16 horas. Foi avaliada a porcentagem de germinação, o índice de velocidade de germinação (IVG), o comprimento de parte aérea (CPA) e de raiz (CR), além de massa seca das plântulas (MSP). O tratamento sem solução crioprotetora das sementes de rainha do abismo proporcionou os maiores valores de germinação, IVG, CPA, CR e MSP. As sementes de rainha do abismo podem ser criopreservadas diretamente no nitrogênio liquido sem a necessidade de soluções crioprotetoras.
\end{abstract}

Palavras-chave: Crioprotetores, vitrificação, nitrogênio liquido.

\begin{abstract}
Cryopreservation of seeds of Brazilian edelweiss (Sinningia leucotricha)

The objective was to evaluate the use of cryogenic solutions in cryopreservation Sinningia leucotricha seeds by the vitrification method in liquid nitrogen. The treatments were: T1 - control: without cryoprotective solution; T2 - PVS1; T3 - modified PVS1; T4 - PVS2; T5 - modified PVS2; T6 - PVS3; T7 - PVS3 modified; T8 - PVS2 + 1\% phloroglucinol. After 15 days of immersion of seeds in $\mathrm{LN}$, the cryotubes were removed and rapidly reheated to a temperature of $40{ }^{\circ} \mathrm{C}$ water bath for 1.5 minutes. Then, the seeds were washed with wash solution for $20 \mathrm{~min}$. Later they were submitted to the germination test which was conducted on blotting paper moistened with distilled water packaged in crystal polystyrene boxes kept in a growth chamber at $25 \pm 2{ }^{\circ} \mathrm{C}$ and 16 hours photoperiod. Was evaluated the germination percentage the germination speed index (GSI), and at the end of the experiment will determine the length of shoot (LS) and root (LR), and dry mass of seedlings (DMS). We used a completely randomized design with eight treatments and five replications, consisting of 100 seeds. The direct submission of the queen of the abyss seeds in liquid nitrogen provided the highest germination values, GSI, LS, LR and DMS. The queen of the abyss seeds can be cryopreserved in liquid nitrogen directly without the need to cryoprotectant solutions.
\end{abstract}

Keywords: Cryoprotectors, vitrification, liquid nitrogen.

\section{INTRODUÇÃO}

Sinningia leucotricha (Hoehne) Moore, pertence à ordem Tubiflorae e família Gesneriaceae, é popularmente conhecida como rainha do abismo, apresenta porte herbácea, com folhas recobertas por densa pilosidade, o que lhe confere uma coloração prateada em contraste com suas flores avermelhadas (IUCHI e LOPES, 1997).

É nativa do Estado do Paraná, mais especificamente das regiões de clima temperado (CHAUTEMS e MATSUOKA, 2003). Produz sementes diminutas, ocorrendo predominantemente em afloramentos de rocha (arenitos) em relevo escarpado, e altitudes de aproximadamente 600 a 800 metros, com reduzidas porções de material detrítico (EMBRAPA, 1974).

Devido à beleza de suas flores e folhas, esta planta tem sido alvo de descontrolada extração e comercialização desregrada (UNEMOTO et al., 2010) e encontra-se atualmente sob risco de extinção, sendo necessária a adoção de medidas que contribuam para sua preservação (BRASIL, 2014), como por exemplo, a conservação de germoplasma (UNEMOTO et al., 2010).

\footnotetext{
DOI: http://dx.doi.org/10.14295/oh.v23i1.921

(1) Recebido em 02/08/2016 e aceito em 17/11/2016

(2) Instituto Federal do Paraná (IFPR), Campus Ivaiporã, Ivaiporã-PR, Brasil.

(3) Doutorando do Programa de Pós-Graduação em Agronomia, Universidade Estadual de Londrina (UEL), Londrina- PR, Brasil. *Autor correspon-

dente: dj_bertoncelli@hotmail.com

(4) Universidade Estadual de Londrina (UEL), Londrina-PR, Brasil.
} 
Para a conservação de germoplasma, a criopreservação tem sido utilizada como um meio efetivo e seguro (TOWILL, 2002), pois consiste na conservação de material biológico em temperaturas ultra-baixas, até $-196^{\circ} \mathrm{C}$ em nitrogênio líquido (NL), mantendo estáveis suas características genéticas a fenotípicas, após o descongelamento. (BAJAJ, 1995; ENGELMANN, 1997).

O ponto mais crítico do processo é o teor de água no material a ser criopreservado. Teores muito baixos levam à desidratação excessiva e morte das células, enquanto elevados levam à formação de cristais de gelo no interior das células, que por sua vez, levam à ruptura do sistema de membranas celulares, à perda de permeabilidade das células e da compartimentalização celular, ocasionando colapso e morte das células (SANTOS, 2001).

No intuito de reduzir os efeitos danosos da agua nas células vegetal, foram desenvolvidas algumas soluções que permitem que as células sobrevivam à exposição de temperatura criogênica (VOLK e WALTERS, 2006), sendo a solução de PVS a mais conhecida e utilizada.

O PVS (plant vitrification solution) foi desenvolvido pelo grupo Sakai. PVS1 foi inicialmente desenvolvido para suspensões de células de aspargo (URAGAMI et al., 1989; URAGAMI 1990). PVS2, originalmente desenvolvido para o tratamento de suspensões celulares de Citrus (SAKAI et al., 1990), foi também utilizado com sucesso para diferentes tipos de explantes de cerca de 200 espécies (SAKAI, 2003), incluindo o alho (VOLK e WALTERS, 2006; NIWATA, 1995). O PVS3 foi inicialmente desenvolvido para wasabi (MATSUMOTO et al., 1995), aspargo (NISHIZAWA et al., 1993) e alho (MAKOWSKA et al., 1999). Porém Teixeira et al. (2014), realizaram algumas alterações nestas soluções crioprotetoras no intuito de melhorar a capacidade de transição destas soluções para o estado vítreo.
No intuito de melhorar o desempenho da solução de PVS2, Vendrame e Faria (2011) adicionaram floroglucinol, e observaram que este mostrou-se efetivo na recuperação e sobrevivência de protocormos de Dendrobium nobile criopreservados por vitrificação. $\mathrm{O}$ floroglucinol (1,3,5-trihidroxibenzene) é um benzenetriol reconhecido por proteger células do estresse oxidativo, inflamação e deterioração por radicais livres, além de favorecer a formação de raízes (KANG et al., 2006; KIM e KIM, 2010).

Dentro do exposto, o objetivo do trabalho foi avaliar o uso de soluções criogênicas na criopreservação de sementes de Sinningia leucotricha.

\section{MATERIAL E MÉTODOS}

As sementes de Sinningia leucotricha foram coletadas de uma planta matriz (Figura 1), mantida em viveiro na Universidade Estadual de Londrina localizada $23^{\circ} 19^{\prime} 42^{\prime}$ 'S, $51^{\circ} 12$ ' $11^{\prime \prime W}$ e altitude $594 \mathrm{~m}$. Logo após a coleta das sementes, estas foram retiradas das cápsulas e determinado o teor de agua e porcentagem de germinação das mesmas, antes de passarem pelo processo de criopreservação.

Para caracterização do lote de sementes, foi realizado o teor de umidade das sementes, determinado através do método da estufa a $105 \pm 3{ }^{\circ} \mathrm{C}$, por 24 horas. $\mathrm{O}$ teste de germinação foi conduzido sobre papel mataborrão umedecido com água destilada na quantidade de 2,5 vezes a massa do papel não hidratado (BRASIL, 2009), acondicionadas em caixas de poliestireno cristal (Gerbox $\left.{ }^{\circledR}\right)$. Foram utilizadas 100 sementes por caixa e cinco caixas por tratamento, que foram mantidas em câmara de crescimento (tipo B.O.D.) à temperatura de 25 $\pm 2{ }^{\circ} \mathrm{C}$, fotoperíodo de 16 horas e intensidade luminosa de $25 \mathrm{mmol} \mathrm{m}^{-2} \mathrm{~s}^{-1}$.
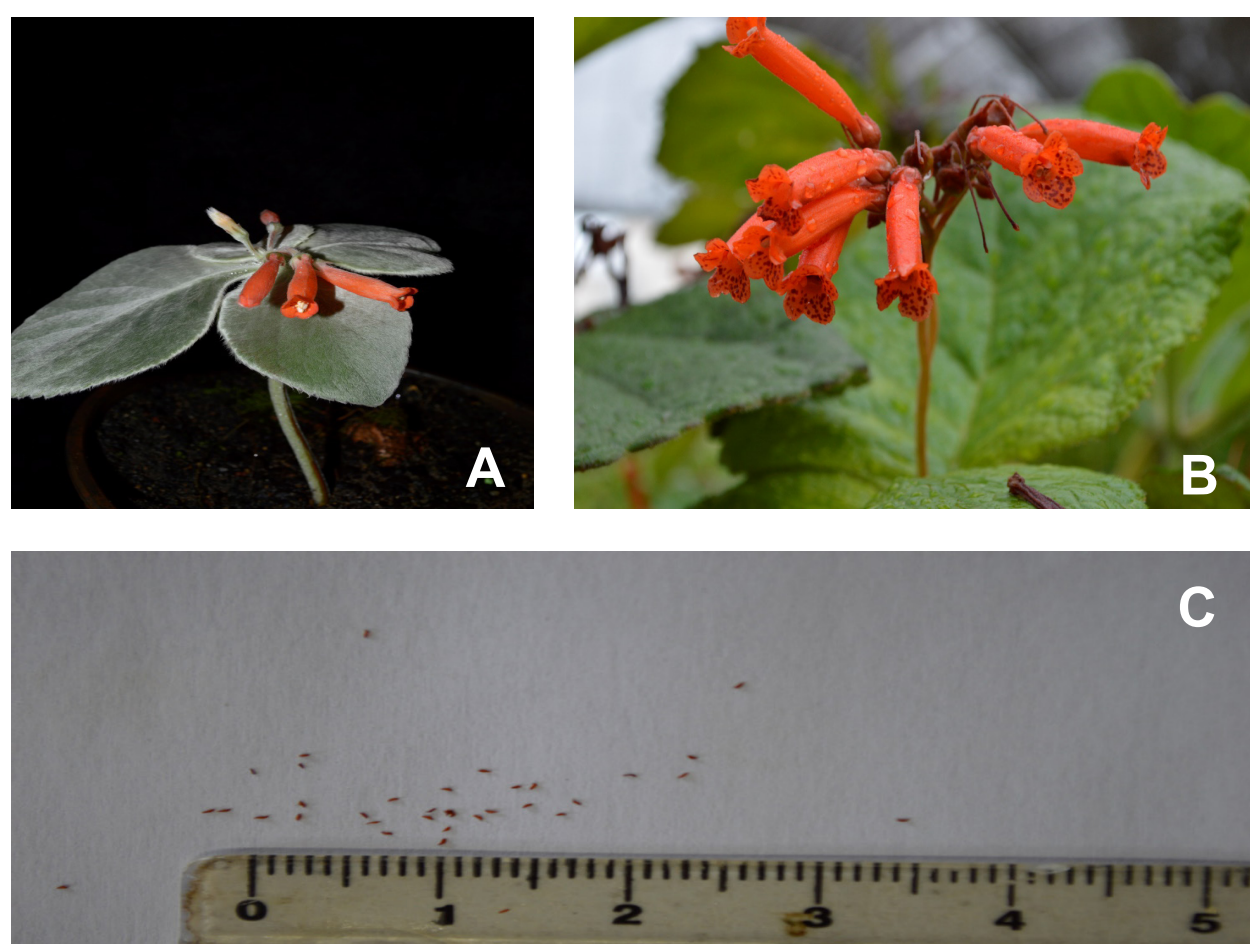

Figura 1. Detalhe da planta (A), flor (B) e sementes (C) de Sinningia leucotricha. Figure 1. Plant Detail (A) Flower (B) and seed (C) of Sinningia leucotricha. 
O delineamento experimental utilizado foi inteiramente casualizado com oito tratamentos e cinco repetições, compostas por 100 sementes cada. Os tratamentos avaliados foram: T1 - controle: sem solução crioprotetora; T2 - PVS1 (composto de 19\% de glicerol, $13 \%$ de etileno glicol, $13 \%$ de polietilenoglicol, $6 \%$ dimetil sulfóxido, 0,5 M de sorbitol, diluído em meio $1 / 2$ MS (MURASHIGE e SKOOG, 1962)); T3 - PVS1 modificado (composto de 19\% de glicerol, 13\% de etileno glicol, $6 \%$ dimetil sulfóxido, $0,5 \mathrm{M}$ de sorbitol, diluído em $1 / 2$ meio MS); T4 - PVS2 (composto de 30\% de glicerol, $15 \%$ de etileno glicol, $15 \%$ dimetil sulfóxido e $0,4 \mathrm{M}$ de sacarose, diluído em $1 / 2$ meio MS); T5 - PVS2 modificado (composto de 37,8 \% de glicerol, 16,7 \% de etileno glicol, 16,5 \% dimetil sulfóxido e $0,4 \mathrm{M}$ de sacarose, diluído em $1 \frac{2}{2}$ meio MS); T6 - PVS3 (composto de $50 \%$ de glicerol, $50 \%$ de sacarose, diluído em agua destilada); T7 - PVS3 modificado (composto de 50\% de glicerol, $50 \%$ de sacarose, $5 \%$ dimetil sulfóxido, diluído em água destilada); T8 - PVS2 + 1\% de floroglucinol.

As sementes foram acondicionadas em criotubos contendo $2 \mathrm{~mL}$ das soluções crioprotetoras e em seguida, submetidas em banho de gelo $\left(0^{\circ} \mathrm{C}\right)$ durante 20 minutos para posterior imersão em nitrogênio líquido (NL) a -196 ${ }^{\circ} \mathrm{C}$. Para o tratamento controle, as sementes foram apenas colocadas no criotubo e imersas em nitrogênio líquido.

Após 15 dias da imersão das sementes em nitrogênio líquido, os criotubos foram removidos e rapidamente descongelados à temperatura de $40^{\circ} \mathrm{C}$, em banho de água, durante 1,5 minutos. A remoção das soluções crioprotetoras foi realizada com auxílio de uma pipeta de Pasteur. Em seguida, as sementes foram lavadas com solução de lavagem (0,4 M de sacarose e $2 \mathrm{M}$ de glicerol) por $20 \mathrm{~min}$. Posteriormente foram submetidas ao teste de germinação, seguindo-se a metodologia supracitada.

Diariamente, foi realizada a contagem do número de sementes germinadas, para estabelecer o índice de velocidade de germinação (IVG), obtido através da fórmula descrita por Maguire (1962) e modificada por Wardle et al. (1991): $\quad \mathrm{IVG}=[\mathrm{N} 1 / 1+\mathrm{N} 2 / 2+\mathrm{N} 3 / 3+\ldots . . \mathrm{Nn} / \mathrm{n})]$, onde, N1, N2, N3 e Nn são o número de sementes germinadas e 1, 2, 3 e n são o número de dias após semeadura.

Trinta dias após a germinação das primeiras sementes (foram consideradas germinadas aquelas que emitiram $3 \mathrm{~mm}$ da radícula) foi determinado o comprimento $(\mathrm{mm})$ da parte aérea (CPA) e do sistema radicular das plântulas (CR), pela medição de dez plantas escolhidas ao acaso. Foi determinada também a massa seca $(\mathrm{mg})$ das plântulas (MSP) realizada em estufa com circulação forçada de ar a $60{ }^{\circ} \mathrm{C}$, até atingirem massa constante.

Os dados foram submetidos à análise de variância (ANOVA) e as médias comparadas pelo teste de Tukey a 5\% de significância, não houve necessidade de transformação dos dados.

\section{RESULTADOS E DISCUSSÃO}

As sementes de rainha do abismo apresentavam antes do tratamento com os crioprotetores e congelamento, porcentagem de germinação média de $59 \% \pm 1$ e teor de água médio de $7,5 \% \pm 1$.

Em relação à porcentagem de germinação, pode-se observar que o melhor tratamento foi o congelamento da semente diretamente no nitrogênio líquido (57\%) (Tabela 1), sem a necessidade de tratamento com as soluções crioprotetoras. As sementes não tratadas com soluções crioprotetoras podem ter apresentado alta sobrevivência por possuírem baixos teores de água (7,5 \%), não necessitando de crioprotetores para reduzir o teor de água das células.

Hirano et al. (2005), trabalhando com sementes da orquídea Bletilla striata, relataram que o teor de água nas sementes é um fator significante na mortalidade dos embriões e, que quanto maior a quantidade de água nas sementes (ideal de 4 a 10\% de umidade), maior a formação de cristais que danificam as membranas celulares, causando a morte do embrião. Isso demonstra que a porcentagem de umidade das sementes é muito mais importante no processo de criopreservação, do que o tratamento com soluções crioprotetoras, as quais devem ser ajustadas apenas para auxiliar na sobrevivência das células vegetais.

Resultado contrário foi observado por Galdiano Jr et al. (2012), que, trabalhando com criopreservação de sementes de híbrido Dendrobium Swartz. Dong Yai, observaram que o congelamento direto das sementes causou morte das mesmas, e que o tratamento que obteve maior sobrevivência após a exposição ao nitrogênio líquido foi a solução de PVS2 + floroglucinol, sendo este resultado explicado pelo fato de que o floroglucinol apresenta propriedades antioxidantes e reduz o estresse oxidativo das células (KANG et al., 2006; KIM e KIM, 2010). 
Tabela 1. Germinação (G), índice de velocidade de germinação (IVG), comprimento de parte aérea (CPA), comprimento de raiz (CR) e massa seca de plântulas (MSP) de sementes de Sinningia leucotricha tratadas com diferentes soluções criogênicas e submetidas à conservação em nitrogênio líquido.

Table 1. Germination (G), germination speed index (GSI), length of the shoot (LS), length of root (LR) and seedling dry mass (SDM) of Sinningia leucotricha seed treated with different solutions and submitted to conservation in cryogenic liquid nitrogen.

\begin{tabular}{|c|c|c|c|c|c|}
\hline Tratamentos & $\mathbf{G}(\mathbf{\%})$ & IVG & CPA (mm) & CR (mm) & MSP (mg) \\
\hline T1 - Controle & $57 \mathrm{a}$ & $3,27 \mathrm{a}$ & $7,6 \mathrm{a}$ & $10,6 \mathrm{a}$ & $0,460 \mathrm{a}$ \\
\hline T2 - PVS1 & $27 \mathrm{c}$ & $1,50 \mathrm{c}$ & $4,8 \mathrm{bc}$ & $8,0 \mathrm{bc}$ & $0,236 \mathrm{~cd}$ \\
\hline T3 - PVS1 modificado & $18 \mathrm{~d}$ & $0,93 \mathrm{~d}$ & $4,8 \mathrm{bc}$ & $5,6 \mathrm{de}$ & $0,232 \mathrm{~d}$ \\
\hline T4 - PVS2 & $27 \mathrm{c}$ & $1,41 \mathrm{c}$ & $5,8 \mathrm{ab}$ & $6,4 \mathrm{~cd}$ & $0,260 \mathrm{~cd}$ \\
\hline T5 - PVS2 modificado & $6 \mathrm{e}$ & $0,31 \mathrm{e}$ & $3,8 \mathrm{bc}$ & $4,2 \mathrm{e}$ & $0,206 \mathrm{~d}$ \\
\hline T6 - PVS3 & $36 \mathrm{~b}$ & $1,91 \mathrm{~b}$ & $3,6 \mathrm{c}$ & $5,2 \mathrm{de}$ & $0,208 \mathrm{~d}$ \\
\hline T7 - PVS3 modificado & $33 \mathrm{bc}$ & $1,49 \mathrm{c}$ & $5,8 \mathrm{ab}$ & $9,4 \mathrm{ab}$ & $0,336 \mathrm{~b}$ \\
\hline T8 - PVS2 + floroglucinol & $39 \mathrm{~b}$ & $2,10 \mathrm{~b}$ & $5,2 \mathrm{bc}$ & $9,2 \mathrm{ab}$ & $0,308 \mathrm{bc}$ \\
\hline CV $(\%)$ & 14,38 & 6,02 & 19,08 & 13,52 & 12,62 \\
\hline
\end{tabular}

*médias seguidas de mesma letra na coluna, não diferem entre si pelo teste de Tukey $(p \leq 0,05)$. T1 - controle: sem solução crioprotetora; T2 - PVS1 (19\% de glicerol, 13\% de etileno glicol, 13\% de polietilenoglicol, 6\% dimetil sulfóxido, 0,5 M de sorbitol, diluído em meio MS 1/2); T3 - PVS1 modificado (19\% de glicerol, $13 \%$ de etileno glicol, $6 \%$ dimetil sulfóxido, $0,5 \mathrm{M}$ de sorbitol, diluído em $1 / 2$ meio MS); T4 - PVS2 (30\% de glicerol, $15 \%$ de etileno glicol, $15 \%$ dimetil sulfóxido e $0,4 \mathrm{M}$ de sacarose, diluído em $1 / 2$ meio MS); T5 - PVS2 modificado (37,8 \% de glicerol, 16,7 \% de etileno glicol, 16,5 \% dimetil sulfóxido e 0,4 M de sacarose, diluído em 1/2 meio MS); T6 - PVS3 (50\% de glicerol, $50 \%$ de sacarose, diluído em agua destilada); T7 - PVS3 modificado (50\% de glicerol, $50 \%$ de sacarose, $5 \%$ dimetil sulfóxido, diluído em água destilada); T8 - PVS2 + 1\% de floroglucinol.

*means followed by the same letter in the column do not differ by Tukey test ( $p \leq 0.05)$. T1 - control: no cryoprotective solution; T2 - PVS1 (19\% glycerol, 13\% ethylene glycol, 13\% polyethylene glycol, 6\% dimethyl sulfoxide, $0.5 \mathrm{M}$ sorbitol, diluted in 1/2 MS medium); T3 - PVS1 modified (19\% glycerol, $13 \%$ ethylene glycol, 6\% dimethyl sulfoxide, $0.5 \mathrm{M}$ sorbitol, diluted in 1/2 MS medium); T4 - PVS2 (30\% glycerol, 15\% ethylene glycol, $15 \%$ dimethyl sulfoxide and $0.4 \mathrm{M}$ sucrose, diluted to $1 / 2 \mathrm{MS}$ medium); T5 - PVS2 modified (37.8\% glycerol, $16.7 \%$ ethylene glycol, $16.5 \%$ dimethyl sulfoxide and 0.4 M sucrose, diluted to 1/2 MS medium); T6 - PVS3 (50\% glycerol, 50\% sucrose, diluted in distilled water); T7 - PVS3 modified (50\% glycerol, $50 \%$ sucrose, $5 \%$ dimethylsulfoxide, diluted in distilled water); T8 - PVS2 + 1\% phloroglucinol.

A desidratação causada pela exposição de tecidos a soluções crioprotetoras é um passo essencial na criopreservação. Isso é crítico para a recuperação e sobrevivência do tecido porque a desidratação permite a redução do conteúdo de água nas células evitando os danos físicos causados por cristais de gelo durante o congelamento (SAKAI et al., 1990), porém essa desidratação pode chegar a um nível crítico onde a célula não consegue mais se regenerar após o período de congelamento.

As soluções que apresentaram maior porcentagem de germinação foram as soluções de PVS2 + floroglucinol, PVS3 e PVS3 modificado (Tabela 1). Desta forma as maiores doses de sacarose, foram benéficas na criopreservação assim como a adição do floroglucinol.

A adição do floroglucinol na solução de PVS2 melhorou a proteção das células, quando comparado com a solução de PVS2, isso provavelmente se deva ao fato do mesmo estar diretamente ligado a proteção das células do estresse oxidativo, inflamação e deterioração por radicais livres, além de favorecer a formação de raízes (KANG et al., 2006; KIM e KIM, 2010). Vendrame e Faria (2011) concluíram que existe um possível efeito sinérgico do floroglucinol quando combinado com glicerol e PVS2, que beneficiam a sobrevivência das células dos protocormos de Dendrobium nobile.

Por sua vez a proteção da semente pelas soluções de PVS3 e PVS3 modificado, esteja provavelmente relacionada à alta concentração de sacarose, pois segundo Santos (2000), os açúcares como a sacarose, trealose e glucose apresentam vantagem em relação às outras soluções crioprotetoras porque eles são excelentes agentes vitrificadores e, além disto, não apresentam toxicidade para as células vegetais mesmo quando se acumulam em grande quantidade no citoplasma.

Açúcares mostram alta eficiência na estabilização das membranas celulares durante o congelamento, em comparação com os crioprotetores tradicionais. Seu efeito protetor está supostamente associado à vitrificação das membranas celulares no citoplasma (HIRSH, 1987; KOSTER, 1991; LEOPOLD, 1990). Evidência do efeito 
protetor dos açúcares pode ser observada em plantas de clima temperado, pois estas plantas acumulam carboidratos solúveis em seus tecidos durante a aclimatação ao frio, aumentando sua tolerância ao congelamento (IMANISHI et al., 1998; SAKAI e YOSHIDA, 1968; STUSHNOFF et al., 1993).

Existem evidências de que o modo de ação dos açúcares envolve múltiplos componentes, sendo que primeiramente os açúcares podem agir como agentes osmóticos externos, removendo o excesso de água intracelular através de um gradiente osmótico (DUMET et al., 1993). Outra hipótese, é que os açúcares podem substituir a água removida das biomoléculas, mantendo as estruturas hidrofílicas na sua orientação hidratada mesmo depois da água ter sido removida.

Para o IVG, observou-se que a imersão direta da semente no nitrogênio líquido proporcionou uma acelerada germinação da semente quando comparado com as sementes que passaram por tratamento prévio com as soluções crioprotetoras as quais apresentaram redução do IVG, sendo que a solução de PVS2 modificado causou o menor índice, provavelmente esta solução ocasionou algum efeito tóxico sobre o processo germinativo, já que apresentou também a menor porcentagem de germinação (Tabela 1).

Molina et al. (2006) trabalhando com criopreservação de sementes de cebola também observaram que a utilização do crioprotetor glicerol diminuiu a porcentagem de germinação e os valores de primeira contagem de germinação das sementes em relação ao congelamento direto no nitrogênio líquido.

Em relação ao comprimento da parte aérea (CPA) o tratamento sem crioprotetor foi o mais expressivo (Tabela 1) não diferindo do PVS2 e PVS3 modificado. Dentre as soluções crioprotetoras, o PVS3 foi o que causou a maior redução no crescimento da parte aérea de plântulas de rainha do abismo (Tabela 1 ).

Assim como o comprimento da parte aérea, o comprimento do sistema radicular (CR) teve maior valor no tratamento sem as soluções crioprotetoras, porém não diferindo dos tratamentos PVS3 modificado e PVS2 + floroglucinol. Dentre os crioprotetores, a solução de PVS2 modificado foi a que causou maiores reduções do comprimento do sistema radicular das plântulas de rainha do abismo (Tabela 1).

Em sementes de cebola o tratamento criogênico, sem uso de crioprotetor, não alterou a germinação nem a composição química das sementes, sendo também o tratamento que apresentou maior número de células em divisão celular. Por outro lado o tratamento com uso de glicerol $50 \%$ como crioprotetor foi prejudicial à qualidade fisiológica e alterou a composição química das sementes de cebola (MOLINA et al., 2006).

Galdiano Jr et al. (2012), observaram que a utilização de crioprotetores na conservação de sementes de Dendrobium Swartz. 'Dong Yai', em nitrogênio líquido, não altera as características de crescimento e desenvolvimento normal da planta.
A massa seca de plântula (MSP) de rainha do abismo também apresentou maior valor no tratamento sem as soluções crioprotetoras. Dentre as soluções criogênicas, o PVS3 modificado foi o que resultou em maiores valores de MSP, seguido pelo PVS2 + floroglucinol (Tabela 1).

As ligações de hidrogênio entre os crioprotetores e a molécula de agua diminui a formação de cristais de gelo, além de promover a estabilização da estrutura quaternária das proteínas de membrana, preservando-as da desidratação. $\mathrm{O}$ uso de crioprotetores para os quais as células têm alta permeabilidade resulta em boa sobrevivência celular. Entretanto, esses crioprotetores podem ser tóxicos ou causar estresse osmótico, levando as células à morte ou modificando sua resposta morfogenética em cultura (SAKAI, 1995). Sendo sempre necessários ajustes em relação ao tipo de crioprotetor e material vegetal em estudo.

\section{CONCLUSÃO}

As sementes de rainha do abismo podem ser criopreservadas diretamente no nitrogênio líquido sem a necessidade de soluções crioprotetoras.

\section{AGRADECIMENTOS}

Os autores agradecem ao CNPq pelo financiamento de bolsa produtividade, e a Capes pelo financiamento da bolsa de doutorado.

\section{REFERÊNCIAS}

BAJAJ, Y.P.S. Cryopreservation of plant cell, tissue, and organ culture for the conservation of germplasm and biodiversity. In: BAJAJ, Y.P.S. (ed.). Biotechnology in agriculture and forestry. Berlin, Heidelberg: SpringerVerlag, 1995. p.3-28.

BRASIL. Ministério da Agricultura, Pecuária e Abastecimento (MAPA). Regras para Análise de Sementes. Brasília: MAPA, 2009. p.399.

BRASIL. Portaria No 443, de 17 de Dezembro de 2014, Ministro de Estado do Meio Ambiente. Diário Oficial da República Federativa do Brasil. Brasília, DF, 18 dez. 2014.

CHAUTEMS, A.; MATSUOKA, C.Y.K. Gesneriaceae. In: Flora Fanerogâmica do Estado de São Paulo. São Paulo: RiMa, 2003. p.75-104.

DUMET, D.; ENGELMANN, F.; CHABRILLANGE, N.; DUVAL, Y.; DEREUDDRE, J. Importance of sucrose for the acquisition of tolerance to desiccation and cryopreservation of oil palm somatic embryos. CryoLetters, v.14, p.243-250, 1993. 
EMBRAPA - Empresa Brasileira de Pesquisa Agropecuária. Levantamento de reconhecimento de solos do estado do Paraná. Londrina: IAPAR; Curitiba: EMBRAPA-SNLCS, 1974. 21p.

ENGELMANN, F. Importance of desiccation for the cryopreservation of recalcitrant seed and vegetatively propagated species. Plant Genetic Resources, v.112, p.9-1, 1997.

GALDIANO JUNIOR, R.F.; LEMOS, E.G.M.; FARIA, R.T.; VENDRAME, W.A. Cryopreservation of Dendrobium hybrid seeds and protocorms as affected by phloroglucinol and Supercool X1000. Scientia Horticulturae, v.148, p.154-160, 2012.

HIRANO, T.; GODO, T.; MII, M.; ISHIKAWA, K. Cryopreservation of immature seeds of Bletilla striata by vitrification. Plant Cell Reports, v.23, n.8, p.534-539, 2005.

HIRSH, A.G. Vitrification in plants as a natural form of cryoprotection. Cryobiology, v.24, n.3, p.214-228, 1987.

IMANISHI, H.T.; SUZUKI, T.; MASUDA, K.; HARADA, $\mathrm{T}$. Accumulation of raffinose and stachyose in shoot apices of Lonicera caerulea L. during cold acclimation. Scientia Horticulturae, v.72, n.3, p.255-263, 1998.

IUCHI, V.L.; LOPES, L.C. Crescimento de Rainhado-abismo (Sinningia leucotricha (Hoehne) Moore Gesneriaceae em resposta à nutrição. Revista Brasileira de Horticultura Ornamental, v.3, n.1, p.53-57, 1997.

KANG, K.A.; LEE, K.H.; CHAE, S.; ZHANG, R.; JUNG, M.S.; HAM, Y.M.; BAIK, J.S.; HYUN, J.W. Cytoprotective effect of phloroglucinol on oxidative stress induced cell damage via catalase activation. Journal Cell Biochemical v.97, n.3, p.609-620, 2006.

KIM, M.M.; KIM, S.K. Effect of phloroglucinol on oxidative stress and inflammation. Food and Chemical Toxicol, v.48, n.10, p.2925-2933, 2010.

KOSTER, K. L. Glass formation and desiccation tolerance in seeds. Plant Physiology, v.96, n.1, p.302-304, 1991.

LEOPOLD, A.C. Coping with desiccation. In: ALSCHER, J.G.; CUMMING, J.R. (eds.). Stress responses in plants: adaptation and acclimation mechanisms. New York: Wiley Liss, 1990. p.37-56.
MAKOWSKA， Z; KELLER, J.; ENGELMANN F. Cryopreservation of apices isolated from garlic (Allium sativum L.) bulbils and cloves. Cryo Letters, v.20, n.3, p.175-182, 1999.

MATSUMOTO, T.; SAKAI, A.; TAKAHASHI, C.; YAMADA, K. Cryopreservation in vitro grown apical meristems of wasabi (Wasabi japonica) by encapsulation vitrification method. Cryo Letters, v.16, p.189-206, 1995.

MOLINA, T.F.; TILLMANN, M.A.A.; DODE, L.B.; VIÉGAS, J. Crioconservação em sementes de cebola. Revista Brasileira de Sementes, v.28, n.3, p.72-81, 2006.

NISHIZAWA, S.; SAKAI,A.;AMANO, Y.; MATSUZAWA, T. Cryopreservation of asparagus (Asparagus officinalis L.) embryogenic suspension cells and subsequent plant regeneration by vitrification. Plant Science, v.91, n.1, p.67-73, 1993.

NIWATA, E. Cryopreservation of apical meristems of garlic (Allium sativum L.) and high subsequent plant regeneration. Cryo Letters, v.16, p.102-107, 1995.

SAKAI, A. Cryopreservation of germplasm of woody plants. In: BAJAJ, Y.P.S. (ed.) Biotechnology in agriculture and forestry. Cryopreservation of plant germplasm. Berlin, Heidelberg: Springer-Verlag, 1995. p.53-69.

SAKAI, A. Proceedings of the International Workshop on Cryopreservation of Bio-Genetic Resources, International Technical Cooperation Center. Rural Development Administration, v.1, p.3-18, 2003.

SAKAI, A.; KOBAYASHI, S.; OIYAMA, I. Cryopreservation of nucellar cell of navel orange (Citrus sinensis Obs. var. Brasiliensis Tanaka) by vitrification. Plant Cell, v.9, n.1, p.30-33, 1990.

SAKAI, A.; YOSHIDA, S. The role of sugar and related compounds in variations of freezing resistance. Cryobiology, v.5, n.3, p.160-174, 1968.

SALOMÃO, A.N. Respostas de sementes de espécies tropicais a exposição ao nitrogênio líquido. Brazilian Journal of Plant Physiology, v.14, n.2, p.133-138, 2002.

SANTOS, I.R.I. Criopreservação de germoplasma vegetal. Biotecnologia Ciência \& Desenvolvimento, v.20, p.6065, 2001. 
SANTOS, I.R.I. Criopreservação: potencial e perspectivas para a conservação de germoplasma vegetal. Revista Brasileira de Fisiologia Vegetal, v.12, p.70-84, 2000.

STUSHNOFF, C.; RAMMELE, R.L.; ESSENSEE, V.Jr.; MCNEIL, M. Low temperature induced biochemical mechanisms: implications for cold acclimation and deacclimation. In: JACKSON, M.B.; BLACK, C.R. (eds.). Interacting stresses on plants in a changing climate. Berlin, Heidelberg: Springer-Verlag, 1993. p.647-657.

TEIXEIRA, A.S., FALTUS, M., ZAMECNIK, J., GONZÁLEZ-BENITO, M.E., MOLINA-GARCIA, A.D. Glass transition and heat capacity behaviors of plant vitrification solutions. Thermochimica Acta, v.593, p.4349,2014

TOWILL, L.E. Cryopreservation of plant germoplasma. In: TOWILL, L.E.; BAJAJ, Y.P.S. Cryopreservation of plant germoplasm II. Berlin, Heidelberg: Springer-Verlag, 2002. P.4-21.

UNEMOTO, L.K.; FARIA, R.T.; ASSIS, A.M.; DESTRO, D. The vegetative development of Sinningia leucotricha Hoehne (Moore) under different levels of shading. Brazilian Archives of Biology and Technology, v.53, n.1, p.47-53, 2010.
URAGAMI, A. Cryopreservation by vitrification of cultured cells and somatic embryos from mesophyll tissue of asparagus. Acta Horticulturae, v.271, p.109-116, 1990.

URAGAMI, A.; SAKAI, A.; NAGAI, M.; TAKAHASHI, T. Survival of cultured cells and somatic embryos of Asparagus officinalis cryopreserved by vitrification. Plant Cell Reports, v.8, n.7, p.418-421, 1989.

VENDRAME, W.A.; FARIA, R.T. Phloroglucinol enhances recovery and survival of cryopreserved Dendrobium nobile protocorms. Scientia Horticulturae, v.128, n.2, p.131135, 2011.

VOLK, G.M.; WALTERS, C. Plant vitrification solution 2 lowers water content and alters freezing behavior in shoot tips during cryoprotection. Cryobiology, v.52, n.1, p.48$61,2006$.

WARDLE, A.D.; AHMED, M.; NICHOLSON, K.S. Allelopathic influence of nodding thistle (Carduns nutans L.) seed on germination and radicle growth of pasture plants. Journal Agriculture Research, v.34, n.2, p.185191, 1991. 